\title{
From the Future to the Past (and Back Again?): A Review of Aleida Assmann's Is Time Out of Joint? On the Rise and Fall of the Modern Time Regime (Ithaca: Cornell University Press and Cornell University Library, 2020)
}

\author{
Joe P. L. Davidson ${ }^{1}$
}

Accepted: 3 May 2021 / Published online: 19 August 2021

(C) The Author(s) 2021

In the mid-2000s, the late writer and critic Mark Fisher was wandering through a shopping centre. As Fisher recounts in Ghosts of My Life (2014), over the mall's sound system, he heard a version of the song 'Valerie', which had recently been a modest hit by the indie pop group The Zutons. However, the song he heard was not the version by The Zutons but, instead, something that appeared to come from the past, the vocal performance and instrumentation closely recalling the soul styles of the 1960s. Fisher came to a natural conclusion: that, unbeknownst to him, The Zutons had covered a little-known soul song. It was only later that he discovered that the version he heard in the shopping centre was, in fact, Amy Winehouse's cover of The Zutons's song, which was deliberately reworked and reconfigured by retro music producer Mark Ronson to mimic the styles and sounds of the past. For Fisher, his confusion regarding the original and the copy is symptomatic of a broader cultural shift. Where once popular music forged a bold path forward-constantly revolutionising itself through new genres, technologies and aesthetics - the 2000s marked a moment when recycling became the keyword, newness displaced by a nostalgic longing for the golden age of pop. As a retro music collector in Carl Neville's dystopia Resolution Way jokes: 'Forget the Futures market [...] I am heavily invested in both the personal and financial senses of that word, in Pasts' (2016: 312).

As Aleida Assmann, a ground-breaking scholar of cultural memory, demonstrates in her new book Is Time Out of Joint?, the preponderance of the pasts market over the futures market speaks to a change in time consciousness in the late twentieth and early twenty-first centuries. Assmann's book, which was first published in German in 2013 and has been lucidly translated by Sarah Clift, is focused on the shifting forms of time consciousness from the eighteenth century to the contemporary moment. As such, it tells a story of how the future fell from grace. Simply put, while the future was once defined by a sense of novelty and alterity, this is no longer the case; our

An author's reply to this comment is available at https://doi.org/10.1007/s10767-021-09413-8.

Joe P. L. Davidson

jpld2@cam.ac.uk

1 University of Cambridge, Cambridge, UK 
horizons of expectation are not filled with the unexpected, the surprising and the original. Instead, the time-to-come appears to offer, at best, more of the same (the eternal recurrence of things that have already happened) and, at worst, catastrophic collapse (whether induced by climate change, technological overreach or economic crisis). Now, in one sense, there is nothing new about this story. From Friedrich Nietzsche's fin de siècle pessimism to Walter Benjamin's critique of progress, the simplistic identification of the future with the gradual realisation of a fundamentally better world has long been suspect. These early critics were cutting against the grain, elaborating an understanding of history that challenged the hegemony of the future. By contrast, Is Time Out of Joint? responds to a situation where scepticism about the alignment of futurity and novelty is generalised and ingrained. The fall of the Berlin Wall in 1989, and the accompanying declaration of the end of history by the neoconservative Francis Fukuyama, marked a turning point, with the disintegration of the Soviet project damning the liberatory desires unleashed by 1917 and depriving the world of revolutionary alternatives to capitalism. More generally, the 1980s and 1990s marked the moment when questions of the past began to dominate. Whether this be the boom in attempts to work through traumatic memories of past catastrophes or the rise of nostalgic trends in popular culture, there is no longer a straightforward movement from past to future, with each step forward accompanied by an anxious glance backwards.

Thanks to a range of publications in the last few decades, the contours of this temporal shift have been partially uncovered. In the 1980s and 1990s, texts such as Helga Nowotny's Time: The Modern and Postmodern Experience (1994 [1989]) and Fredric Jameson's Postmodernism, or, the Cultural Logic of Late Capitalism (1991), for all their differences, traced the shifting shape of time consciousness in the late twentieth century, a story that has been refined by more recent contributions like Francois Hartog's Regimes of Historicity: Presentism and Experiences of Time (2015 [2003]), Hans Ulrich Gumbrecht's Our Broad Present: Time and Contemporary Culture (2014 [2011]) and Enzo Traverso's Left-Wing Melancholia: Marxism, History and Memory (2016). These studies are, for the most part, infused by a sense of melancholia and regret. The collapse of the future has resulted in a number of pathological consequences, from an inability to conceive of a transformative movement away from the degraded and decaying contours of twenty-first-century capitalism to a fundamental corruption of historiography itself. Fisher's temporal disorientation in the shopping centre has become our general condition, an inability to chart a movement from the past through the present and into the future resulting in feelings of helplessness, perplexity and frustration. Ironically, the critics of our new temporal condition also manifest one of its central elements: nostalgia or more accurately, as Kate Eichhorn comments of the temporal consciousness of the contemporary feminist movement, they are nostalgic 'for the conditions under which there was nothing [...] to be nostalgic about', longing for a time when the transformative potential of the future appeared natural and necessary, when the whole world was bent on upturning the past (2015: 259).

Is Time Out of Joint? strikes a refreshingly different tone. Assmann confronts the travails of the modern time regime unsentimentally, having no illusions about the value of the mode of temporality that dominated until the mid-twentieth century. 
Now, the book is clear in the opening three chapters-on the present in modernity, the rise of modern historiography, and the components of the modern time regimethat the emergence of a new form of time consciousness in eighteenth-century Europe opened up productive possibilities. In contrast to the older cyclical modes of time consciousness, history was more than the repetition of the same; the temporal movement of the world was laced with utopias, revolutions, and ruptures. Yet as Assmann intimates in these early chapters, and in contrast to some of the other accounts mentioned, care should be taken not to idealise this pattern of historical understanding. While the modern time regime blasted open the impasse of the future, it imposed a blockage on the past. In switching orientation from the past to the future, the former was discounted and delegitimised. Assmann, discussing the faith in modernisation that dominated in the mid-twentieth century, puts this point as follows: 'This generation of modern reformers is emblematic of an exclusive focus on the future that is incompatible with a return to the past-particularly to one's own past' (7). In other words, the modern time regime concatenated 'a break from the past and the prohibition of memory', the great leap into unknown futures requiring a cut with what had come before (68). There is a Nietzschean undercurrent to this story, Assmann's genealogy telling of a slave revolt in temporal consciousness. While the modern time regime understood itself to be radically other to the conceptions of history that came before, it was simply a reversal of the latter: past and future exchanged places but no transfiguration occurred.

The lopsided nature of the modern time regime contains the seeds of its fall. The final three chapters - focused on the temporality of late modernity, the anxieties and confusions that this has provoked, and the possibility for repairing time consciousness- highlight the instabilities at the heart of the modern time regime. The experience of the twentieth century unpicked the preponderance of the future and forced the gaze backwards. Most obviously, the First World War, the degeneration of the Russian Revolution, the rise of fascism and the Holocaust punctured a hole in the idea that the future would bring a better world. In Assmann's words: 'Under these conditions, the future no longer serves as the Eldorado of our hopes and dreams, while at the same time any heady talk about progress has begun to sound more and more hollow' (4). More profoundly, the disasters of this historical moment rejuvenated and recharged the temporal realm of the past. In the second half of the twentieth century, an injunctive to remember the traumas of history emerged. The modern time regime's dismissal of the past, where historical events could be easily forgotten, proved inadequate in the post-Holocaust world, its amnesiac attitude failing in the face of the desire for cultural memory. In this way, a temporal shift has begun to take shape, where the chasm between the past and the future is steadily bridged by mnemonic practices: 'The pendulum has swung back; the forgetting of the past and the obsession with the future that were built into the modern time regime are being dismantled in light of new ways of reactivating the past' (198). Intense consciousness of past traumas exerts a drag on expectations for the future; there are unhealed historical wounds that pervade the contemporary world.

For Assmann, the rejuvenation of the past, rather than something to be rued, has fostered a productive rebalancing. The crisis of the future was a necessary one; it is only by disturbing the idea that rupture and transformation should be valued above 
all else that 'those aspects of time that the modern temporal regime had dogmatically excluded' can be brought back into the frame (197). As Chapter 6 emphasises, the rise of cultural memory, and associated ideas about collective identity, holds the key to repairing the temporal breaches opened by modern time consciousness. In this way, Is Time Out of Joint? offers normative justification for Assmann's work on memory in books such as Cultural Memory and Western Civilization: Functions, Media, Archives (2011 [1999]). Memory is not only an aspect of contemporary culture, an empirical phenomenon to be studied, but it also has decisive social and political value. The recognition of difference, awareness of the pervasive power of historically rooted oppressions, perception of the barbarism that hides under the surface of seemingly civilised artefacts: all this is underpinned by the memory of catastrophe. In a way that would please Benjamin, the return of the past has given renewed power to people defeated by the dominant movement of history: 'While the future-oriented modern temporal regime silently passed over the victims of history, the temporal regime of the new memory culture has brought these voices back into the present' (216).

Assmann's study tells an expansive story of the shifting forms of time consciousness since the eighteenth century, representing both a culmination of her previous work on cultural memory and a bold intervention into contemporary debates on modern temporality. In doing so, Is Time Out of Joint? combines pithiness with creativity. On the one hand, in offering an overview of three hundred years of history, it is necessary to economise, Assmann drawing out what is key to both the rise and the fall of the modern time regime. On the other hand, Is Time Out of Joint? is far from a dry schemata of different forms of time consciousness, the book interspersing conceptual innovation with reflections on some of the key cultural figures of the twentieth century. Whether it is Charles Baudelaire on the distinctiveness of the present in modernity, Virginia Woolf on the discontinuous nature of historical development, or James Baldwin on the exclusion of African Americans from the white narrative of history, Assmann subtly brings to the fore the power of literature as a means of diagnosing the dominant pattern of temporality. Furthermore, Assmann's extended debates with other key scholars of temporality not only display a generous attentiveness to alternative perspectives but also help the reader pinpoint exactly what is distinctive and original about her argument. The engagement with the work of Gumbrecht, Hartog and John Torpey in the fifth chapter of the book is exemplary in this regard, Assmann teasing out both the value and the limits of these scholars' scepticism about the fall of the modern time regime.

Is Time Out of Joint? makes an elegant and convincing case for taking another look at contemporary forms of time consciousness. However, Assmann's Owl of Minerva approach, the synoptical overview of tendencies that have shaped temporality since the eighteenth century, occasionally leaves a desire for more. One area where Assmann's argument could be pushed further concerns the relationship between the modern time regime and colonial relations of domination. Assmann's focus is on temporal consciousness in Europe and North America, the aim of the book to trace 'a continental shift [that] is taking place in the structure of Western temporality' (5; emphasis added). This focus is understandable; Assmann's book is an ambitious one and clearly some geographical focalising is necessary. However, Is 
Time Out of Joint? contains some tantalising remarks that suggest that the coordinates of Western time consciousness cannot be fully understood without an account of colonialism. For example, she states that one of the tragedies of modernity was 'the decimation of Indigenous peoples' (174), gestures towards the 'establishment of worldwide colonial powers' at the moment of the rise of modern time consciousness (69) and associates the colonisation of North America with an intense sense of futurity (74-80). ${ }^{1}$ These comments suggest that colonialism was not merely incidental to the modern time regime but constitutive to it. Most obviously, progress, one of the key conceptual innovations of the modern time regime, offered ideological justification for European superiority. As everyone from Aimé Césaire and Frantz Fanon to Dipesh Chakrabarty and Walter Mignolo recognises, the 'denial of coevalness', whereby the world is divided up into the advanced and the backwards, was key to the European colonial project (Fabian, 2014: 32). Space was converted into time; the peoples of the world were arranged on a progressive ladder of development, with Europe at the top.

Assmann's book, then, hints at the possibility of overcoming 'abyssal thinking', the conceptualisation of the West as a distinct analytical unit that can be separated from the world more generally, but does not fully escape from its strictures (de Sousa Santos, 2007: 45). This concern becomes even more pressing when the question of the fall of the modern time regime is considered. Now, again, Assmann briefly notes that 'Jewish, postcolonial and feminist' perspectives disturbed the paradigm of modernisation in the 1980s (8) and provides an account of the Black critique of American futurism offered by writers such as Ralph W. Ellison and Toni Morrison (87-91). Nevertheless, one of the key processes of the post-war period is largely absent from Is Time Out of Joint?: decolonisation. ${ }^{2}$ There are reasons to think that the fall of the modern time regime was intimately linked to both the formal process by which formerly colonial nations gained political independence and the broader social and cultural experiments in delinking that occurred in this period. If progress partly functioned to maintain a relationship of temporal inequality, then the desire of postcolonial nations to forge their own path and reimagine lines of development posed a challenge to Western temporality, suggesting that European colonial powers no longer had a monopoly on the future. As such, a question can be posed: Alongside the increasing consciousness of the memory of catastrophes, was the provincialisation of progress a reason for the disintegration of the modern time regime?

A second area where Is Time Out of Joint? provokes some questions is the environment. Assmann alludes to the affinity between her story of the shifting forms of time consciousness and the impending climate catastrophe, making the following statement on the final page of the book: 'Armed with the knowledge of the natural

\footnotetext{
1 Assmann's (2014) work on global memory is suggestive here, highlighting that the rise of concern with the past is something that cuts across national boundaries. For instance, in Assmann's account of the Palestinian Nakba, she notes the entanglement of settler colonialism, modern temporality, and cultural trauma: 'With 1948, a new chronology began for Israeli society. An empty and unshaped ground was needed on which to build a new future [...]' (2018: 290).

${ }^{2}$ Elsewhere, Assmann has offered some useful suggestions on the relationship between decolonisation and memory in postimperial contexts (Assmann, 2015; Assmann, 2018a, b).
} 
sciences and technology, humans are continually destroying the future through irreversible disturbances in ecological equilibria, but they are also generating the future by means of new notions of sustainability' (232). Let me be clear, although Assmann gestures towards how consciousness of ecological devastation has undercut the confident embrace of the future (see 4, 63, 205-206), climate is not a central theme of the book. However, there is an interesting resonance between the account of the fall of the modern time regime and the critique of progress that is often voiced amongst thinkers concerned with the Anthropocene. Donna Haraway puts this point in particularly stark terms in her influential book on the Chthulucene: 'Historically situated relational worldings make a mockery both of the binary division of nature and society and of our enslavement to Progress and its evil twin Modernization' (2016: 50). In other words, increasing awareness of humanity's imbrication with the nonhuman suggests that the future is not entirely in our control; history is not the product of human action alone. Now, Is Time Out of Joint? offers an important check on the critique of progress found amongst contemporary environmentalists. As Assmann makes clear, the collapse of faith in the future is not something new; it has a long history that stretches far beyond the intense sense of catastrophe that has emerged in the last decade. In other words, the Anthropocene might be the final nail in the coffin of the modern time regime (or, less charitably, Haraway might be flogging a dead horse), but we should not mistake this for a novel development.

Still, we might wonder whether crossing the threshold from the Holocene to the Anthropocene complicates the account of the rise and fall of the modern time regime offered in Is Time Out of Joint? Assmann tacitly positions the environmental crisis as one more challenge to the future; it is not qualitatively distinct from the other threats on the horizon. This perspective is understandable in contextual terms. Talk of the Anthropocene was nascent in 2013 when Is Time Out of Joint? was first published, and it should not surprise readers that the word is not mentioned in the book. Furthermore, the alignment of the impending climate disaster with more familiar anxieties about the future is defensible. The exuberant tone of some Anthropocene discourse, that climate change should foster a fundamental rethinking of our conceptual framework tout court, risks undermining the continuities in temporal consciousness. Simply put, the fear of climate disaster is not radically distinct from that of nuclear apocalypse or global war. Nevertheless, there is one aspect of the Anthropocene that might pose a challenge to the perspective developed in Is Time Out of Joint?: deep time. The idea that human-induced climate change has altered the environment in a fundamental fashion, something that will last for hundreds of thousands of years, prompts a question about the entire framework of the rise and fall of the modern time regime. This story might be embedded into a bigger shift in time consciousness, one that is less focused on the relationship between past, present and future and, instead, concerned with the place of humanity in the massive scale of geological time itself. ${ }^{3}$ On this basis, we might ask, in line with a recent intervention by Ian Baucom (2020), can these two scales, the shallow time of

\footnotetext{
${ }^{3}$ This is something that Assmann (2019) hints at in a recent essay, where she discusses the multiple scales of time in the Anthropocene.
} 
modern temporality and the deep time of the Anthropocene, be interlaced and interweaved, such that both are held within the gaze simultaneously?

It is part of the power of Is Time Out of Joint? that, as in the cases of colonialism and climate, space is left for enrichment and radicalisation; Assmann's suggestive clues will hopefully give succour to new intellectual inquiry. There is one area, however, where I wondered whether the book overemphasises the value of the break between the modern time regime and its aftermath. The argument of Is Time Out of Joint? risks the premature abandonment (rather than reforming or rejuvenation) of some of the central concepts of modernity. That is to say, are revolution and utopia, as Assmann seems to imply, exhausted? The nuance of Is Time Out of Joint? should be emphasised here. For Assmann, the reconfiguration of temporality in recent decades does not mean that the future is devoid of hope for different social relations. For instance, she suggests that Ernst Bloch's repository of liberatory desires remains 'an irreplaceable resource for each new generation' (231). Indeed, Assmann, in her essay 'Civilising Societies' (2013), proffers an image of the future based around the twin concepts of recognition and respect. That said, Assmann's proposal for a 'second meaning of the future' (231), a conception of the time-to-come that contests and overcomes the ruptures of the modern time regime, suggests a more measured perspective than Bloch's intense longing for the novum:

Instead of a break in time and clearing everything away for a tabula rasa, an affective connection can be affirmed to what exists and what is past that one does not want to ignore, neglect, or lose — much less destroy—but rather seeks to safeguard. (231)

After the failures of the revolutionary experiments of the twentieth century, the appeal of this careful attitude to the future is easy to understand. Nevertheless, a question remains about whether the second meaning of the future proposed by Assmann is adequate to the contemporary conjuncture. In particular, I would contend, some of the concepts associated with the modern time regime-such as the desire for a revolutionary break and the need for radical utopian imaginarieshave, if anything, become more vital in recent years. In the context of a capitalist socio-economic system that, alongside its perennial failure to meet human needs in a equitable and just fashion, is rapidly driving the planet to the brink of climate catastrophe, is now the time to abandon all of the dreams of rupture associated with the modern time regime? Kim Stanley Robinson, one of the foremost living writers of utopian fiction, rightly notes that: 'It has become a case of utopia or catastrophe, and utopia has gone from being a somewhat minor literary problem to a necessary survival strategy' (2016: 9). In other words, if we desire a viable future in which the environmental preconditions for human life are secured, then a radical break from prevailing social relations is required, and required quickly.

In this sense, Assmann highlights the tragic situation we find ourselves in. While utopia and revolution may be more necessary than ever, they are also less convincing than ever. Assmann is correct to state that the idea that 'the modern temporal regime - which is now 'out of joint' — could be reset once again, much as one does with a dislocated shoulder' is ultimately inadequate; there is no going behind the collapse of modern temporality, we cannot put cultural memory or apocalyptic horizons 
back in the bottle (229). That said, there are forms of negotiation between the modern time regime and its aftermath that, while rejecting the straightforward revival of the future, attempt to critically excavate its undetonated energy. We can return here to Mark Fisher's temporal confusion in the shopping centre. Alongside the negative moment of this experience, that pop music had lost its future, it also had a positive moment for Fisher: retro phenomenon take us back to a time when everything was bent on the future. To understand this coming together of nostalgia and futurity, Fisher turns to Jacques Derrida's notion of hauntology, elaborated in Spectres of Marx (1994), which, like Assmann's book, also plays with Hamlet's famous declaration that time is out of joint. The haunting presence of lost futures, those moments of the twentieth century which promised liberation but failed to deliver it, mediates between the modern time regime and its aftermath, simultaneously registering the failures of the past and returning to it to retrieve a renewed hope for the future. As Fisher puts it, the constant return to pop music's pasts has a radical underside: 'It is about refusing to give up the ghost or [...] the refusal of the ghost to give up on us. The spectre will not allow us to settle into/for the mediocre satisfactions one can glean in a world governed by capitalist realism' (2014: 22). The evocation of hauntology allows us to retain something of the modern time regime, even as we confront its collapse, offering a fragile basis for thinking the possibility for breaks and ruptures in the present via a detour through what Bloch fruitfully calls the 'undischarged past' (1991 [1935]: 308). So can we see the second meaning of the future jostling alongside its first meaning, the two embracing one another in a dialectical relationship of reformation and development?

The fact that Is Time Out of Joint? raises questions such as this is testament to its value. Assmann has offered scholars of contemporary temporality a firm platform for understanding a range of issues that, whether explicitly addressed in the text or not, shape the experience of the past and the future. Is Time Out of Joint? is certainly not the last word on the modern time regime; its haunting presence in the cultural consciousness means that, for good or bad, we can never quite lay it to rest. This is not a problem; the book is all the better for not providing finality. Instead, it represents the first word on temporality in the twenty-first century, offering a productive framework for addressing our disturbed and unsettled time consciousness.

Open Access This article is licensed under a Creative Commons Attribution 4.0 International License, which permits use, sharing, adaptation, distribution and reproduction in any medium or format, as long as you give appropriate credit to the original author(s) and the source, provide a link to the Creative Commons licence, and indicate if changes were made. The images or other third party material in this article are included in the article's Creative Commons licence, unless indicated otherwise in a credit line to the material. If material is not included in the article's Creative Commons licence and your intended use is not permitted by statutory regulation or exceeds the permitted use, you will need to obtain permission directly from the copyright holder. To view a copy of this licence, visit http://creativecommons.org/ licenses/by/4.0/.

\section{References}

Assmann A. (1999 [2011]). Cultural Memory and Western Civilization: Functions, Media, Archives. Cambridge: Cambridge University Press. 
Assmann, A. (2013). Civilizing societies: Recognition and respect in a global world. New Literary History, 44(1), 69-91.

Assmann, A. (2014). Transnational memories. European Review, 22(4), 546-556.

Assmann, A. (2015). Memories of post-imperial nations. In D. Rothermund (Ed.), Memories of PostImperial Nations: The Aftermath of Decolonization (pp. 1945-2013). Cambridge University Press.

Assmann, A. (2018a). One land and three narratives: Palestinian sites of memory in Israel. Memory Studies, 11(3), 287-300.

Assmann, A. (2018b). Towards a new ethos of history? In S. Helgesson and J. Svenungsson (Eds.), The Ethos of History. New York: Berghahn.

Assmann, A. (2019). Conclusion: A creed that has lost its believers? Reconfiguring the concepts of time and history. In M. Tamm and L. Olivier (Eds.) Rethinking Historical Time. London: Bloomsbury.

Baucom, I. (2020). History $4^{\circ}$ Celsius: Search for a Method in the Age of the Anthropocene. Durham, NC: Duke University Press.

Bloch, E. (1991). Heritage of Our Times. Trans. N. Plaice and S. Plaice. Cambridge: Polity.

De Sousa Santos, B. (2007). Beyond abyssal thinking: From global lines to ccologies of knowledges. Review, 30(1), 45-89.

Derrida, J. (1994). Spectres of Marx: The State of the Debt, the Work of Mourning, and the New International. Trans. P. Kamuf. London: Routledge.

Eichhorn, K. (2015). Feminism's there: On post-ness and nostalgia. Feminist Theory, 16(3), 251-264.

Fabian, J. (2014). Time and the Other: How Anthropology Makes its Object. New York: Columbia University Press.

Fisher, M. (2014). Ghosts of My Life: Writings on Depression, Hauntology and Lost Futures. Winchester: Zero Books.

Gumbrecht, H. U. (2014). [2011]) Our Broad Present: Time and Contemporary Culture. New York: Columbia University Press.

Haraway, D. (2016). Staying with the Trouble: Making Kin in the Chthulucene. Durham, NC: Duke University Press.

Hartog, F. (2015 [2003]). Regimes of Historicity: Presentism and Experiences of Time. Trans. S. Brown. New York: Columbia University Press.

Jameson, F. (1991). Postmodernism, or, the Cultural Logic of Late Capitalism. Durham, NC: Duke University Press.

Neville, C. (2016). Resolution Way. London: Repeater.

Nowotny, H. (1994 [1989]). Time: The Modern and Postmodern Experience. Trans. N. Plaice. Cambridge: Polity.

Robinson, K. S. (2016). Remarks on Utopia in the age of climate change. Utopian Studies, 27(1), 1-15.

Traverso, E. (2016). Left-Wing Melancholia: Marxism, History and Memory. New York: Columbia University Press.

Publisher's Note Springer Nature remains neutral with regard to jurisdictional claims in published maps and institutional affiliations. 